07

\title{
Прецизионная калибровка уровня легирования кремнием эпитаксиальных слоев арсенида галлия
}

\author{
(C) Д.В. Мохов ${ }^{1}$, Т.Н. Березовская ${ }^{1,2}$, А.Г. Кузьменков ${ }^{2,3, \uparrow, ~}$ \\ Н.А. Малеев ${ }^{2,4}$, С.Н. Тимошнев ${ }^{1}$, В.М. Устинов ${ }^{2,3,5}$ \\ ${ }^{1}$ Санкт-Петербургский национальный исследовательский академический \\ университет РАН \\ ${ }^{2}$ Физико-технический институт им. А.Ф. Иоффе РАН, Санкт-Петербург \\ ${ }^{3}$ Научно-технологический центр микроэлектроники и субмикронных \\ гетероструктур РАН, Санкт-Петербург \\ ${ }^{4}$ Санкт-Петербургский государственный электротехнический университет \\ „ЛЭТИ“ \\ ${ }_{5}^{5}$ Санкт-Петербургский политехнический университет Петра Великого \\ ๑ E-mail: kuzmenkov@mail.ioffe.ru
}

Поступило в Редакцию 22 июня 2017 г.

Рассмотрен подход к обеспечению прецизионной калибровки уровня легирования кремнием эпитаксиальных слоев арсенида галлия, основанный на исследовании зависимости концентрации носителей заряда в тестовом слое GaAs от температуры источника кремния методами на основе эффекта Холла и CV-профилирования. Для измерений параметров используются стандартные или аттестованные методики измерений и средства измерений утвержденного типа. Показано, что использование метода CV-профилирования для контроля концентрации носителей заряда в тестовом слое GaAs при тщательной оптимизации измерительной процедуры обеспечивает наивысшую точность и достоверность калибровки уровня легирования эпитаксиальных слоев с относительной погрешностью не более $2.5 \%$.

DOI: $10.21883 /$ PJTF.2017.19.45086.16931

При изготовлении полупроводниковых гетероструктур СВЧ-транзисторов на основе соединений $A^{3} B^{5}$ методом молекулярно-пучковой эпитаксии в ряде случаев критически важно получать эпитаксиальные слои с воспроизводимым заданным уровнем легирования. В частности, концентрация носителей заряда в канале и пороговое напряжение гетероструктурных полевых транзисторов сильно зависят от уровня 
легирования донорных слоев, а в гетеробиполярных транзисторах уровень легирования коллекторного слоя $n$ - $\mathrm{GaAs}$ определяет величину пробивного напряжения база-коллектор, ограничивающего достижимый уровень выходной мощности [1].

Для измерения уровня легирования эпитаксиальных слоев широко используется ряд методов, в том числе метод на основе эффекта Холла [2], вольт-емкостное (или CV) профилирование [3], электрохимическое вольт-емкостное (или ECV) профилирование [4], вторичная ионная масс-спектрометрия (ВИМС) [5]. В трех первых методах фактически измеряется концентрация носителей заряда, тогда как в последнем непосредственно измеряется концентрация атомов легирующей примеси. В таблице приведены сравнительные характеристики указанных методов [6].

Выбор конкретного метода в первую очередь определяется требованиями к точности калибровки уровня легирования эпитаксиальных слоев. Допустимое отклонение уровня легирования от проектных значений для современных СВЧ-транзисторов ограничено диапазоном $\pm 5-10 \%$, поэтому прецизионная калибровка уровня легирования отдельных эпитаксиальных слоев транзисторных гетероструктур является задачей на пределе технических возможностей используемых методов измерений. В настоящей работе рассматривается подход к обеспечению прецизионной калибровки уровня легирования кремнием эпитаксиальных слоев арсенида галлия (GaAs), основанный на исследовании зависимости концентрации носителей заряда в тестовом слое GaAs от температуры источника кремния методами на основе эффекта Холла и CV-профилирования. При этом для измерений параметров используются стандартные или аттестованные методики и средства измерений утвержденного типа.

При измерениях эпитаксиальных слоев $n$-типа с концентрацией легирующей примеси в диапазоне $10^{16}-10^{18} \mathrm{~cm}^{-3}$ методы на основе эффекта Холла и CV-профилирования представляются предпочтительными ввиду их меньшей погрешности. Кроме того, они метрологически обеспечены, т. е. имеются средства измерений (СИ) утвержденного типа и методики измерений с оцененными характеристиками погрешности.

Ввиду высоких требований к точности калибровки уровня легирования для современных СВЧ-транзисторов на основе соединений $A^{3} B^{5}$ точность измерений методом на основе эффекта Холла в этом случае может оказаться недостаточной, и метод CV-профилирования представ-

Письма в ЖТФ, 2017, том 43, вып. 19 
ляется более предпочтительным, несмотря на относительно сложную экспериментальную процедуру, обусловленную необходимостью изготовления тестовых диодных структур. Кроме того, благодаря более высокой точности и локальности измерений метод CV-профилирования подходит для исследования неоднородности концентрации носителей заряда по площади эпитаксиальной структуры, а также позволяет получить профиль распределения концентрации носителей заряда по толщине слоя и оценить однородность легирования по глубине слоя.

Для калибровки уровня легирования кремнием эпитаксиальных слоев GaAs $n$-типа проводимости, выращенных методом молекулярнопучковой эпитаксии, были изготовлены специальные калибровочные структуры, содержащие однородно легированный атомами кремния тестовый эпитаксиальный слой GaAs на полуизолирующей подложке GaAs. Толщина слоя (от 1 до $2 \mu \mathrm{m}$ ) выбиралась в зависимости от уровня легирования таким образом, чтобы минимизировать влияние границы с подложкой (возможное частичное обеднение за счет влияния подложки).

Основными технологическими параметрами, влияющими на уровень легирования, являются скорость роста тестового слоя GaAs и температура источника кремния, поэтому перед выполнением калибровки уровня легирования осуществлялась калибровка скорости роста GaAs. Для этого проводились измерения спектров фотолюминесценции специальной калибровочной структуры, содержащей сверхрешетку $(\mathrm{GaAs} / \mathrm{AlAs}) \times 10$ с номинальными толщинами слоев $10 \mathrm{~nm}$. Измерения выполнялись по аттестованной методике ФР.1.27.2012.12687 [7] на установке RPMSigma (регистрационный номер в Госреестре СИ 46682-11) с использованием дифракционной решетки 300 grooves $/ \mathrm{mm}$ и полупроводникового инжекционного лазера с длиной волны излучения $788 \mathrm{~nm}$. По положению пиков в спектре фотолюминесценции определялась средняя толщина слоев GaAs в сверхрешетке (квантовых ям), после чего вычислялась скорость роста GaAs (с учетом известной длительности роста отдельных слоев калибровочной структуры).

Для выращенных тестовых эпитаксиальных слоев GaAs, легированных атомами $\mathrm{Si}$, концентрация носителей заряда $N$ была измерена двумя способами: методом на основе эффекта Холла и методом $\mathrm{CV}$-профилирования. Измерения методом на основе эффекта Холла выполнялись по стандартной методике ГОСТ 25948-83 [8] с дополнением в части подготовки образца к измерениям: четыре индиевых контакта

Письма в ЖТФ, 2017, том 43, вып. 19 
Сравнительные характеристики методов, используемых для определения концентрации легирующей примеси $n$-типа в слоях $\mathrm{GaAs}$

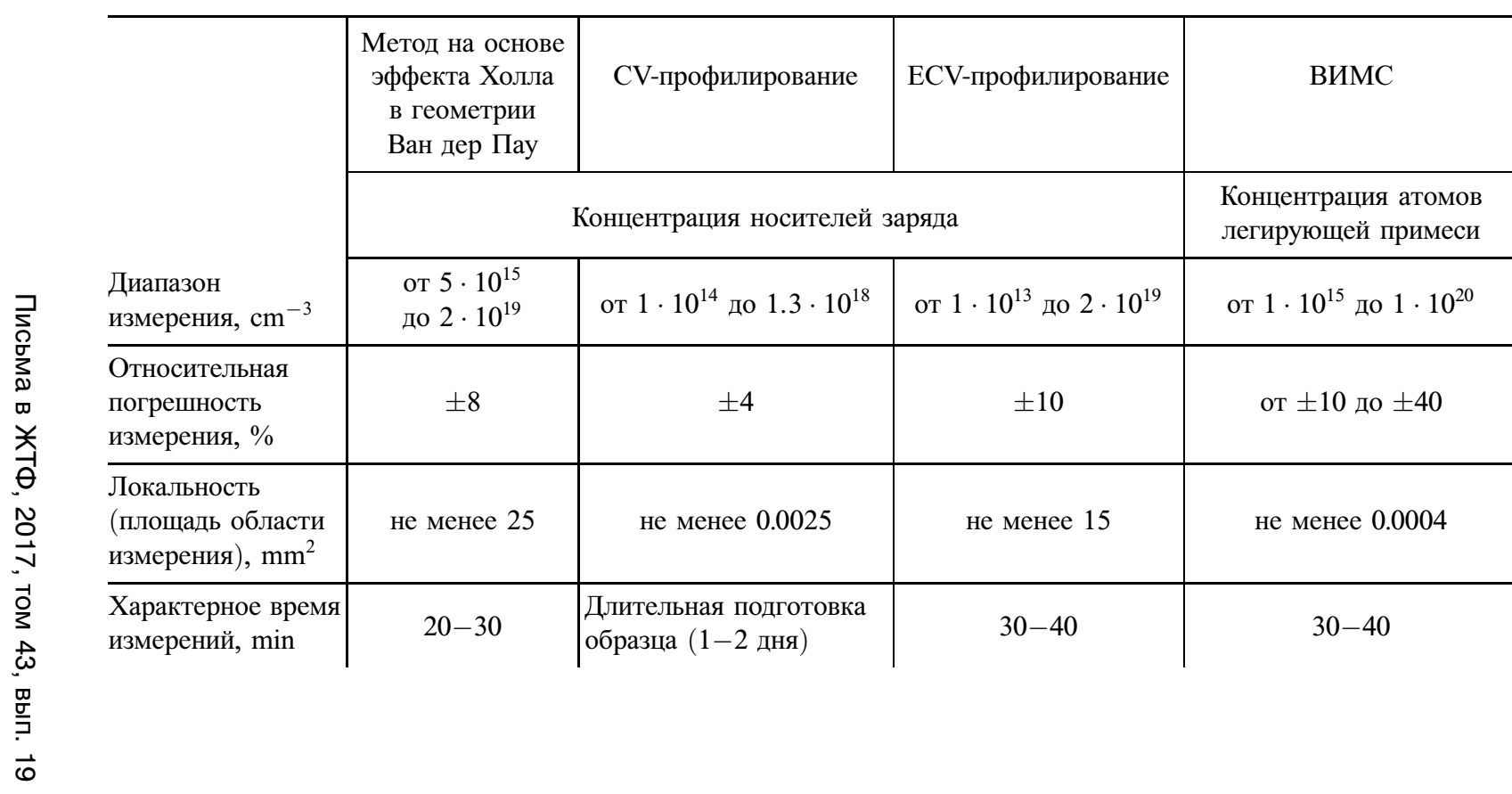




\begin{tabular}{|c|c|c|c|c|}
\hline $\begin{array}{l}\text { Разрушение } \\
\text { образца }\end{array}$ & $\begin{array}{l}\text { Нелокальное } \\
\text { (выкалывание } \\
\text { кусков) }\end{array}$ & $\begin{array}{l}\text { Локальное (формирова- } \\
\text { ние тестового диода) }\end{array}$ & $\begin{array}{l}\text { Локальное (ямка трав- } \\
\text { ления и две точки кон- } \\
\text { тактирования) }\end{array}$ & $\begin{array}{l}\text { Локальное (ямка травле- } \\
\text { ния), возможны ограниче- } \\
\text { ния по размеру образца }\end{array}$ \\
\hline $\begin{array}{l}\text { Достоинства } \\
\text { метода }\end{array}$ & $\begin{array}{l}\text { Простота реализа- } \\
\text { ции; наличие СИ } \\
\text { утвержденного } \\
\text { типа }\end{array}$ & $\begin{array}{l}\text { Измерение профиля кон- } \\
\text { центрации; возможно ис- } \\
\text { пользование легирован- } \\
\text { ных или нелегированных } \\
\text { подложек; наличие про- } \\
\text { мышленно выпускаемых } \\
\text { СИ утвержденного типа }\end{array}$ & $\begin{array}{l}\text { Измерение профиля } \\
\text { концентрации; возмож- } \\
\text { но использование ле- } \\
\text { гированных или неле- } \\
\text { гированных подложек; }\end{array}$ & $\begin{array}{l}\text { Измерение профиля кон- } \\
\text { центрации; возможно ис- } \\
\text { пользование легированных } \\
\text { или нелегированных под- } \\
\text { ложек; }\end{array}$ \\
\hline $\begin{array}{l}\text { Недостатки } \\
\text { метода }\end{array}$ & $\begin{array}{l}\text { Высокая погреш- } \\
\text { ность; необходи- } \\
\text { мость использова- } \\
\text { ния высокоомной } \\
\text { или полуизолиру- } \\
\text { ющей подложки }\end{array}$ & $\begin{array}{l}\text { Высокая трудоемкость } \\
\text { подготовки образца }\end{array}$ & $\begin{array}{l}\text { Высокая погрешность; } \\
\text { отсутствие СИ утверж- } \\
\text { денного типа }\end{array}$ & $\begin{array}{l}\text { Высокая погрешность; от- } \\
\text { сутствие стандартных об- } \\
\text { разцов для калибровки; } \\
\text { высокая стоимость изме- } \\
\text { рительного оборудования }\end{array}$ \\
\hline
\end{tabular}


наносились на лицевую сторону структуры по углам образца в форме квадрата со стороной размером $7 \pm 1 \mathrm{~mm}$ и затем вжигались. Измерения проводились на установке для измерения эффекта Холла HMS-3000 (регистрационный номер в Госреестре СИ 45517-10) при значениях постоянного тока 0.10 и $1.00 \mathrm{~mA}$ и значении магнитной индукции 0.55 T. При измерении концентрации носителей заряда в качестве исходных данных используется значение толщины тестового слоя GaAs. Измерения методом CV-профилирования выполнялись по аттестованной методике ФР.1.31.2017.26704 [9] с использованием прецизионного LCR-измерителя E4980A Agilent (регистрационный номер в Госреестре СИ 70676-09). На поверхности структуры формировались тестовые диоды Шоттки коаксиальной формы с диаметром измерительного электрода $200 \mu \mathrm{m}$. Результаты измерений вольт-фарадных характеристик обрабатывались в рамках классической модели полного обеднения, которая дает адекватные результаты для однородно легированных структур и структур с плавным изменением профиля легирования.

В качестве технологических параметров, определяющих характеристики исследуемых структур, выступали скорость роста тестового слоя $\mathrm{GaAs}$, определенная по результатам калибровок, и температура $T$ источника легирующей примеси $(\mathrm{Si})$. Измеренные зависимости $\ln N$ от $T$ представлены на рисунке, $a$. Для некоторых образцов наблюдается заметное отклонение от ожидаемой линейной зависимости.

Для гарантии воспроизводимого получения проектной толщины исследуемых слоев GaAs из рассмотрения были исключены образцы, для которых значение скорости роста слоев GaAs находится за пределами заданного диапазона $1.6-1.8 \AA / \mathrm{s}$. Кроме того, из дальнейшего рассмотрения были исключены образцы, в которых по результатам $\mathrm{CV}$-измерений была обнаружена существенная неоднородность профиля легирования. На рисунке, $b$ приведены зависимости концентрации носителей заряда от температуры источника кремния, полученные после исключения недостоверных результатов.

Из представленных на рисунках, $a$ и $b$ данных следует, что коэффициент качества линейной аппроксимации $R$ после исключения недостоверных результатов калибровки увеличился с 0.94 до 0.99 .

Полученные результаты свидетельствуют о возможности достижения высокой точности калибровки уровня легирования слоев $n$-GaAs во всем рассматриваемом диапазоне концентраций $10^{16}-10^{18} \mathrm{~cm}^{-3} \mathrm{c}$ использованием предложенного подхода, основанного на исследовании 

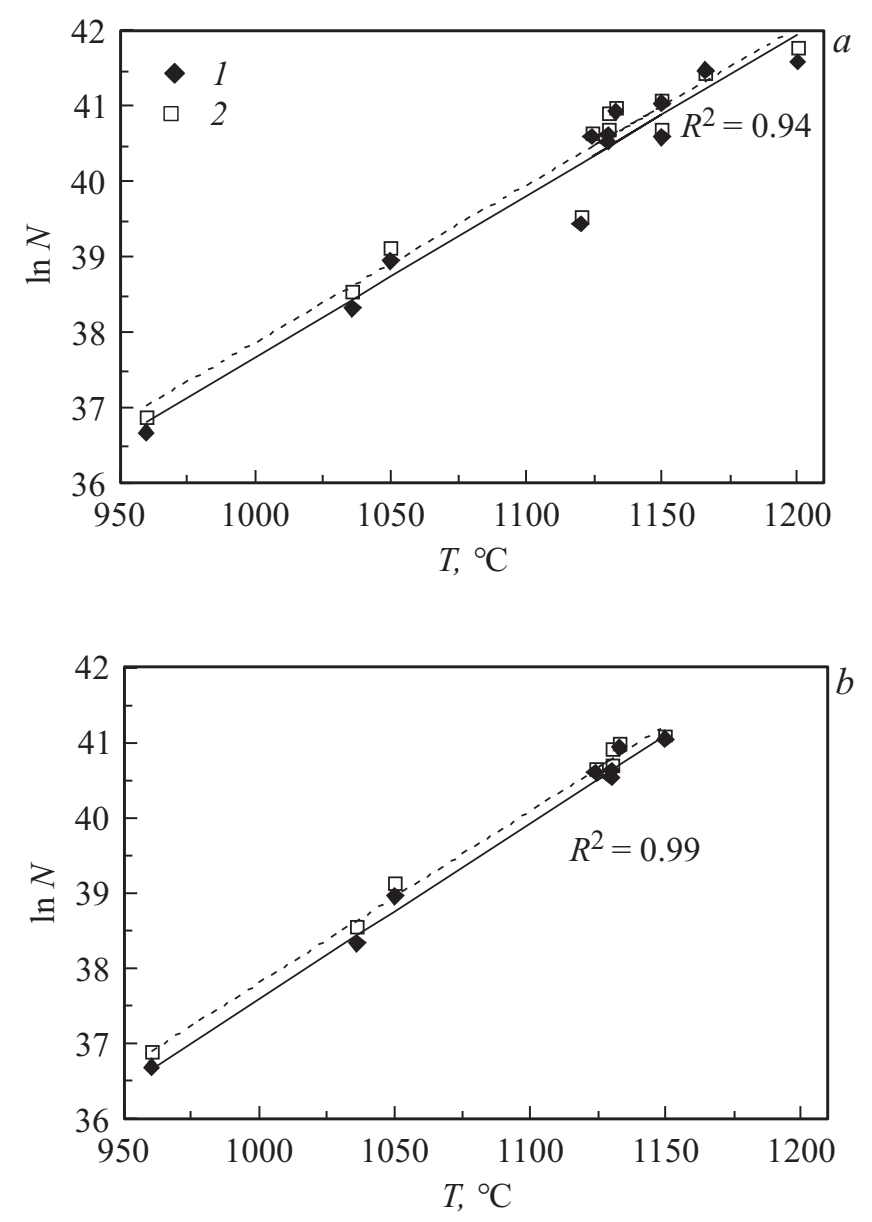

Зависимости концентрации носителей заряда $N$ от температуры источника кремния $T$ до $(a)$ и после $(b)$ исключения недостоверных результатов. 1 - измерение $\mathrm{CV}$-методом, 2 - измерение методом Холла.

зависимости концентрации носителей заряда в тестовом слое GaAs от температуры источника кремния методами на основе эффекта Холла и $\mathrm{CV}$-профилирования в сочетании с предложенными критериями исключения недостоверных результатов (поддержание скорости роста слоев

Письма в ЖТФ, 2017, том 43, вып. 19 
GaAs в заданном диапазоне опорного значения и предварительный контроль степени однородности легирования методом CV-профилирования). При этом, как продемонстрировано в аттестованной методике ФР.1.31.2017.26704 [9], использование метода CV-профилирования для контроля концентрации носителей заряда в тестовом слое GaAs при тщательной оптимизации измерительной процедуры обеспечивает наивысшую точность и достоверность калибровки уровня легирования эпитаксиальных слоев с относительной погрешностью не более $2.5 \%$.

А.Г. Кузьменков и В.М. Устинов выражают благодарность Министерству образования и науки РФ за финансовую поддержку (соглашение о предоставлении гранта № 14.578.21.0212 от 29.09.2016 г., идентификационный номер RFMEFI57816X0212).

\section{Список литературы}

[1] Liu W. Fundamentals of III-V devices: HBT's, MESFET's, and HFETs/HEMTs. N.Y.: John Wiley, 1999. P. 520.

[2] Standard test methods for measuring resistivity and Hall coefficient and determining Hall mobility in single-crystal semiconductors. ASTM Designation F76-08, Annual Book of ASTM Standards. V. 10.04.2011.

[3] Reynolds N.D., Panda C.D., Essick J.M. // Am. J. Phys. 2014. V. 82. Iss. 3. P. 196.

[4] Blood P. // Semicond. Sci. Technol. 1986. V. 1. N 1. P. 7.

[5] Shepherd F.R., Vandervorst W., Lau W.M. et al. // Proc. of the 5th Int. Conf. Washington, DC, 1985. P. 350-352.

[6] Schroder D.K. Semiconductor material and device characterization. 3rd ed. New Jersey: John Wiley and Sons, 2006. P. 800.

[7] ФР.1.27.2012.12687. Методика измерения средней толщины слоев арсенида галлия в полупроводниковых материалах методом фотолюминесценции. СПб.: СПб АУ НОЦНТ РАН, 2012. 13 с.

[8] ГОСТ 25948-83. Арсенид галлия и фосфид галлия монокристаллические. Измерение удельного электрического сопротивления и коэффициента Холла. Введ. 01.01.85. Изм. № 1 (ИУС 6-1989). 16 с.

[9] ФР.1.31.2017.26704. Стандарт организации. Структуры полупроводниковые на основе арсенидов металлов третьей группы. Методика измерений концентрации носителей заряда и определения распределения этой величины по толщине структуры методом вольт-емкостного профилирования. МИ 02359503334-2017. СПб.: СПбАУ РАН, 2017. 33 с. 